\title{
Avaliação da agressividade e da diversidade genética de Sclerotinia sclerotiorum em tabaco no sul do Brasil
}

\author{
Marcia Peripolli ${ }^{1}$, José Antônio Martinelli ${ }^{1}$, Carla Andréa Delatorre ${ }^{2}$
}

\begin{abstract}
${ }^{1}$ Universidade Federal do Rio Grande do Sul, Departamento de Fitossanidade, Av. Bento Gonçalves, 7712, 91540-000, Porto Alegre, RS, Brasil; ${ }^{2}$ Universidade Federal do Rio Grande do Sul, Departamento de Plantas de Lavoura, Av. Bento Gonçalves, 7712, 91540-000, Porto Alegre, RS, Brasil Autor para correspondência: José Antônio Martinelli (jamfito@ufrgs.br).

Data de chegada: 24/11/2016. Aceito para publicação em: 12/09/2017.
\end{abstract}

$10.1590 / 0100-5405 / 172537$

\section{RESUMO}

Peripolli, M.; Martinelli, J.A.; Delatorre, C.A. Avaliação da agressividade e da diversidade genética de Sclerotinia sclerotiorum em tabaco no sul do Brasil. Summa Phytopathologica, v.44, n.2, p.170-177, 2018.

A cultura do tabaco tem enfrentado crescentes problemas com doenças nas lavouras do sul do Brasil nos últimos anos. Dentre elas, o mofo branco, causada por Sclerotinia sclerotiorum, tem se destacado. O perfil genético do patógeno ou de seus níveis de agressividade, assim como de resistência em genótipos de tabaco, são ainda escassos. Assim, avaliou-se o perfil genético de 33 isolados de S. sclerotiorum de diferentes municípios dos estados do Rio Grande do Sul, Santa Catarina, Paraná e São Paulo, e da agressividade de 10 isolados em cinco genótipos de tabaco. A agressividade foi testada em casa de vegetação, inoculando-se micélio do fungo em hastes de plantas de tabaco mediante perfuração com palito de dente estéril. O perfil genético dos 33 isolados foi avaliado pela técnica de microssatélites. Isolados do fungo e genótipos de tabaco apresentaram diferentes perfis de agressividade e resistência, respectivamente. Foram detectados 114 alelos com média de 11 alelos por locus e clones não foram observados. Alguns marcadores apresentaram alelo nulo em alguns genótipos, em especial o marcador 99, o qual foi nulo em 14 isolados. Alelos exclusivos foram observados para $61 \%$ dos isolados. A análise da informação do conteúdo de polimorfismo (PIC) foi altamente informativa para todos os marcadores. Os isolados provenientes de diferentes Estados do Sul do Brasil não formaram grupos distintos, indicando que o local não foi um fator determinante da variabilidade. A análise de Cluster indicou que as populações menores, originárias do Paraná e Rio Grande do Sul não diferem geneticamente da população maior de Santa Catarina.

Palavras-chave: mofo branco, caracterização molecular, microssatélites, SSR

\section{ABSTRACT}

Peripolli, M.; Martinelli, J.A.; Delatorre, C.A. Evaluation of agressiveness and genetic diversity of Sclerotinia sclerotiorum in tabaco in southern Brazil. Summa Phytopathologica, v.44, n.2, p.170-177, 2018.

Tobacco has faced rising problems due to diseases in Southern Brazil in recent years. Among the main diseases, the white mold caused by Sclerotinia sclerotiorum has significant impact. Information about the genetic profile of the pathogen, its level of aggressiveness, as well as the resistance of tobacco genotypes is still scarce. Therefore, in this study, we evaluated the genetic profile of 33 isolates of $S$. sclerotiorum from different places in the states of Rio Grande do Sul, Santa Catarina, Paraná and São Paulo, and the aggressiveness of 10 isolates in five tobacco genotypes. Aggressiveness was tested by inoculating fungus celium on stalks of tobacco plants in a greenhouse. The genetic profile of the 33 isolates was assessed by microsatellite technique. Fungus isolates and tobacco genotypes showed different profiles of aggressiveness and resistance, respectively. A total of 114 alleles were detected with an average of 11 alleles per locus and no clones were observed. Some markers showed null allele in some genotypes, particularly marker 99, which was null in 14 isolates. Unique alleles were found for $61 \%$ of the isolates. The analysis of polymorphism information content (PIC) was highly informative for all markers. Isolates from different States of Southern Brazil did not form distinct groups, indicating that the origin site was not a determining factor of variability. The Cluster analysis indicated that smaller populations from Paraná and Rio Grande do Sul do not differ genetically from the larger population from Santa Catarina.

Keywords: white mold, molecular characterization, microsatellite, SSR.

Produzido em diversos países para a fabricação de cigarros, charutos e assemelhados, o tabaco (Nicotiana tabacum L.) movimenta bilhões de dólares anualmente na economia mundial e contribui com a economia de mais de 150 países. O Brasil é o segundo maior produtor de tabaco e se destaca por ser o principal exportador. O setor emprega mais de 2,2 milhões de pessoas (2). Muitas doenças podem interferir na produtividade $(13,29)$. Dentre as doenças pode-se destacar o mofo branco, causado pelo fungo Sclerotinia sclerotiorum (Lib.) de Bary que pode devastar lavouras e causar prejuízos significativos (3). Em algumas regiões, o plantio de tabaco é sucessivo, não havendo intervalo para rotação de cultura, favorecendo a permanecia do patógeno no campo. Em casos extremos de incidência de doença, áreas inteiras são abandonadas, isso porque o insucesso dos controles químico e cultural, a falta de cultivares resistentes ao patógeno e a persistência dos escleródios no solo são alguns dos problemas encontrados no combate à doença (28). Os escleródios, ao caírem no solo, podem 
ser incorporados aos restos culturais durante o preparo do solo para o plantio (15). Além disso, S. sclerotiorum pode servir de inóculo para outras plantas suscetíveis utilizadas na rotação de cultura (24).

O patógeno é altamente agressivo. Muitos estudos relatam que diferentes isolados de $S$. sclerotiorum podem desenvolver diferentes perfis de agressividade em plantas $(16,19,30,31)$. A agressividade pode ser definida como a capacidade relativa de um patógeno de colonizar e causar danos às plantas, sem distinguir entre aspectos quantitativos e qualitativos. A agressividade é muitas vezes avaliada por caracteres quantitativos elementares do ciclo de vida do patógeno, como a eficiência de infecção, período de latência, período infeccioso ou tamanho da lesão (20).

S. sclerotiorum é um dos mais devastadores patógenos de plantas (28), e a alta diversidade genética da população tem sido alvo de alguns estudos $(12,14)$. Conhecer a estrutura e a dinâmica da população de S. sclerotiorum é a chave para entender a história e a distribuição geográfica do patógeno nos mais diferentes hospedeiros (12). Para os estudos de caracterização populacional de $S$. sclerotiorum, os marcadores microssatélites são largamente utilizados $(5,9,12,14,18$, 25). Microssatélites são marcadores baseados em sequências curtas repetitivas, amplificadas a partir de sequências únicas que flanqueiam as repetições havendo, portanto, necessidade de conhecimento prévio do genoma.

São muitos os desafios para o controle do mofo branco no cultivo do tabaco. Melhorias no sistema de manejo e o desenvolvimento de cultivares resistentes podem contribuir para a diminuição da doença no campo. Os programas de melhoramento genético de plantas, a fim de desenvolverem cultivares de tabaco resistente à doença, necessitam entender e conhecer os padrões genéticos populacionais do patógeno. Assim, este estudo teve o objetivo de avaliar a agressividade e a diversidade genética de S. sclerotiorum isolados de lavouras de tabaco do sul do Brasil.

\section{MATERIAL E MÉTODOS}

Os isolados de $S$. sclerotiorum foram obtidos a partir de plantas infectadas pela doença, sendo 27 isolados da cultura do tabaco, dois da cenoura, um do nabo, um da soja, um da alface e um da canola, originários dos estados do Sul do Brasil (Tabela 1). Os escleródios foram cultivados em meio batata dextrose ágar (BDA) acidificado com ácido lático a $25 \%$ para $\mathrm{pH} 5,5$. Inicialmente, os escleródios foram desinfestados em álcool $70 \%$, seguido de hipoclorito de sódio a $1 \%$, ambos por 1 minuto, e enxaguados com água destilada. As placas foram incubadas em $\mathrm{BOD}$ a $20^{\circ} \mathrm{C}$ por sete dias. As colônias produziram escleródios, os quais foram colhidos e colocados em placas de Petri por 24 horas em incubadora a $27^{\circ} \mathrm{C}$ para secagem. Após, foram armazenados em microtubos e acondicionados em freezer a $-20^{\circ} \mathrm{C}$ para a preservação.

Dois experimentos em casa de vegetação avaliaram a agressividade dos isolados do fungo em quatro genótipos de tabaco do grupo varietal Virgínia e um genótipo de tabaco silvestre. Foram utilizados dez isolados de $S$. sclerotiorum, sendo oito da cultura do tabaco, um da cultura da alface e um da cultura do feijão. Cada planta foi individualizada em vaso de polietileno com capacidade de $500 \mathrm{~mL}$ contendo substrato à base de turfa e acondicionada em casa de vegetação. As inoculações foram realizadas na haste das plantas de tabaco mediante perfuração com palito de dente estéril contendo um fragmento do micélio do fungo com meio de cultura. As plantas do primeiro e do segundo experimentos foram inoculadas 77 e 91 dias após a semeadura, respectivamente. As plantas do segundo experimento estavam com 14 dias a mais de cultivo do
Tabela 1. Código do isolado, município, estado, e hospedeiros de origem dos isolados utilizados.

\begin{tabular}{llll}
\hline Código do inóculo & Município & UF & Hospedeiro \\
\hline 1 & Campo do Tenente & PR & Tabaco \\
3,4 & Irati & PR & Tabaco \\
$2,9,10,20,21,22$, & Araranguá & SC & Tabaco \\
$23,24,27,28,29,31$ & & & \\
$6,17,26,30$ & Sombrio & SC & Tabaco \\
7 & Maracajá & SC & Tabaco \\
$11,12,13,14,25$ & Içara & SC & Tabaco \\
19 & Santa Rosa do Sul & SC & Tabaco \\
5 & Anta Gorda & RS & Tabaco \\
51 & Santa Maria & RS & Cenoura \\
52 & Santa Maria & RS & Nabo \\
53 & Augusto Pestana & RS & Soja \\
54 & Santa Maria & RS & Alface \\
55 & Santa Maria & RS & Cenoura \\
58 & Vacaria & RS & Canola \\
\hline TOTAL: 33 isolados & & & \\
\hline & & & \\
\hline
\end{tabular}

que as plantas do primeiro experimento, porém com desenvolvimento similar. Isso ocorreu devido ao ambiente mais frio, o qual permitiu que as plantas se desenvolvessem mais lentamente do que as plantas do primeiro experimento. Os experimentos foram conduzidos na cidade de Cachoeirinha - RS, no período de março a julho de 2015, com variação de temperatura entre 8 e $26^{\circ} \mathrm{C}$.

O tamanho da lesão, em mm, na haste das plantas de tabaco ao longo do tempo foi medido com paquímetro digital, considerando-se a sua progressão longitudinal. As medições foram feitas diariamente a partir do surgimento das lesões, por cinco dias no primeiro experimento e por oito dias no segundo experimento. As lesões tiveram início após o oitavo e o terceiro dia das inoculações no primeiro e no segundo experimentos, respectivamente.

O delineamento experimental adotado foi o delineamento completamente casualizado com 10 repetições, sendo que unidade amostral era constituída por uma planta. No primeiro experimento, em função da elevada taxa de mortalidade, os isolados foram agrupados conforme o tipo de sintomas. Grupo 1 = mais agressivos, causando morte das plantas acima de 58,4\% em média, identificados pelos isolados 10, 11, 17, 19 e 21. Grupo 2 = isolados menos agressivos, que causaram mortalidade abaixo de $8,4 \%$ em média, identificados pelos isolados 1, 4, 5, 54 e 56. Procederam-se as análises estatísticas via metodologia de modelos mistos, utilizando-se o PROC MIXED do SAS. No segundo experimento, a progressão da lesão na haste das plantas ao longo do tempo foi obtida através da análise de modelos de coeficientes aleatórios.

O DNA de cada isolado de Sclerotinia sclerotiorum foi extraído a partir de $100 \mathrm{mg}$ do pellet celular do micélio do fungo após um cultivo de sete a dez dias em meio BDA. O DNA genômico foi extraído através do uso de kit comercial Wirad (Promega ${ }^{\circledR}$ ) seguindo as recomendações do fabricante. O DNA obtido foi mensurado em Qubit ${ }^{\mathrm{TM}}$ Invitrogen TM . O DNA genômico foi amplificado usando dez marcadores SSR previamente descritos em S. sclerotiorum por Sirjusingh \& Kohn (26). As reações de amplificação continham 30 ng de DNA genômico, 100 $\mu \mathrm{M}$ de cada um dos desoxirribonucleotídeos (dATP, dGTP, dTTP e 
Tabela 2. Porcentagem de morte dos genótipos de tabaco inoculados com cada um dos isolados no primeiro experimento.

\begin{tabular}{|c|c|c|c|c|c|c|c|c|c|c|c|c|}
\hline \multirow[t]{2}{*}{ Genótipos } & \multicolumn{6}{|c|}{ Isolados GRUPO 1} & \multicolumn{6}{|c|}{ Isolados GRUPO 2} \\
\hline & 10 & 11 & 17 & 19 & 21 & Média & 1 & 4 & 5 & 54 & 56 & Média \\
\hline $1 *$ & 80 & 80 & 100 & 70 & 70 & 80 & 10 & 10 & 0 & 0 & 0 & 4 \\
\hline 2 & 90 & 40 & 60 & 70 & 50 & 62 & 0 & 0 & 20 & 0 & 0 & 4 \\
\hline 3 & 10 & 60 & 80 & 30 & 0 & 36 & 0 & 20 & 30 & 10 & 10 & 14 \\
\hline Média & 58 & 66 & 76 & 46 & 46 & 58,4 & 2 & 20 & 12 & 6 & 2 & 8,4 \\
\hline
\end{tabular}

* genótipos: 1 tabaco silvestre, 2, 3, 4 e 5 tabacos do grupo varietal Virgínia. $\mathrm{n}=10$.

dCTP), uma unidade da enzima Taq DNA polimerase, $0,5 \mu \mathrm{M}$ de cada primer do par, $2 \mu \mathrm{M}$ de tampão de reação (50 mM TRIS pH 8,3; 2 $\mathrm{mM} \mathrm{MgCl} ; 20 \mathrm{mM} \mathrm{KCl} ; 10 \mu \mathrm{g}$ de BSA, 0,25\% de ficol 400; $10 \mathrm{mM}$ de tartrazine) e água ultra pura livre de DNAse e RNAse, totalizando um volume de reação de $50 \mu \mathrm{L}$. As amplificações foram realizadas em termociclador, por meio do seguinte programa: $95^{\circ} \mathrm{C}$, por 8 minutos, para uma desnaturação inicial, seguido de 35 ciclos de desnaturação a $95^{\circ} \mathrm{C}$, pareamento dos primers a $55^{\circ} \mathrm{C}$ ou $60^{\circ} \mathrm{C}$ e extensão a $72^{\circ} \mathrm{C}$, por 30-45 segundos, com 5 minutos de extensão no ciclo final (26). As amplificações foram avaliadas por eletroforese em gel de agarose (2\%), corado com intercalante de DNA Sybr SAFE (Invitrogen ${ }^{\circledR}$ ) e fotodocumentadas sob luz ultravioleta em transluminador por Sistema Alpha $\left(\right.$ Innotech $\left.^{\circledR}\right)$. Todas as amostras amplificadas em gel de agarose foram submetidas à corrida em gel de poliacrilamida ( 9 a 13\%) para verificação do polimorfismo. As bandas polimórficas obtidas foram avaliadas em comparação com marcador molecular de tamanho conhecido e estimado o tamanho de cada amplicon (alelo).

As estimativas entre os alelos e locus foram calculadas diretamente a partir dos dados genotípicos utilizando o programa GENEPOP 4.5.1 (23) e PAST versão 2.17c. Para isso, os dados genotípicos foram inseridos em uma matriz. Para cada par de loci de dentro de cada amostra, a estimativa imparcial do valor P foi indicada, assim como o erro padrão através do GENEPOP 4.5.1 e em seguida, um teste global (método de Fisher) para cada par de loci foi realizado. As estimativas de diversidade genética foram calculadas com a ajuda dos programas GENEPOP 4.5.1 (23) e através da análise do conteúdo de informação de polimorfismo (PIC). Para investigar a similaridade genética entre isolados foi realizada análise de coordenadas Principais (PCA) no programa PAST versão $2.17 \mathrm{c}$. Uma matriz de distância baseada nos alelos comuns entre isolados foi usada para mostrar a estrutura genética dos isolados. Além disso, uma árvore foi construída utilizando o agrupamento pelas médias aritméticas não ponderadas (UPGMA) com base na matriz de microssatélites em comum entre os isolados através do programa PAST versão $2.17 \mathrm{c}$.

\section{RESULTADOS}

\section{Teste de agressividade}

No primeiro experimento, os isolados 10, 11, 17, 19 e 21, do grupo 1 , foram os mais agressivos, causando uma mortalidade média de $58,4 \%$, enquanto que os isolados $1,4,5,54$ e 56 , do grupo 2 , causaram uma mortalidade média de apenas $8,4 \%$ (Tabela 2).

Em função do alto índice de mortalidade das plantas, não foi possível avaliar estatisticamente a progressão das lesões para os isolados do grupo 1. Isso demonstra maior agressividade desses isolados sobre os genótipos testados.

Para o grupo 2 de isolados, a análise do comprimento longitudinal da lesão $(\mathrm{mm})$ na haste das plantas de tabaco indicou que os genótipos 3,4 e 5 foram significativamente mais suscetíveis que os genótipos 1 e 2 (Tabela 3). Apenas cultivar teve efeito significativo ( $\mathrm{p}<0,0001)$.

No segundo experimento, o progresso da lesão ao longo do tempo foi significativo para todos os genótipos, independente do isolado inoculado. A interação tríplice foi significativa $(\mathrm{p}=0,0160)$, indicando que o progresso da doença para os isolados se diferenciou em cada genótipo. Todos os genótipos, independentemente de isolados, apresentaram coeficiente de regressão linear significativo $(p<0,05)$.

Somente os isolados 1 e 54, independentemente dos genótipos, apresentaram coeficiente de regressão linear não significativo $(p>0,05)$. Os Isolados que apresentaram progresso significativo da doença por genótipo foram os isolados 4, 10 e 11 no genótipo 2; isolado 17 nos genótipos 1, 2 e 5; isolado 19 nos genótipos 1, 2, 3 e 5; e isolados 21 e 56 nos genótipos 3 e 4 (Tabela 5).

\section{Análise de diversidade genética}

Foram avaliados 10 loci SSR em 33 isolados de S. sclerotiorum. Houve amplificação de produtos usando os conjuntos de primers em todas as amostras. A análise das amplificações em poliacrilamida permitiu visualizar bandas polimórficas. Através dos perfis eletroforéticos obtidos com cada microssatélite, os tamanhos dos amplicons foram estimados e colocados em uma matriz. Dos 33 isolados testados neste estudo, 14 (42\%) não amplificaram o SSR 99.

A análise de desequilíbrio de ligação foi gerada a partir da inserção dos dados da matriz genética no programa GENEPOP. Os conjuntos que apresentaram valores de $\mathrm{p}$ acima de 0,05 indicaram que os loci

Tabela 3. Comprimento longitudinal da lesão $(\mathrm{mm})$ no caule das plantas de tabaco inoculadas com os isolados de Sclerotinia sclerotiorum do grupo $2(1,4,5,54,56)$ no primeiro experimento.

\begin{tabular}{ccc}
\hline Genótipos & Comprimento da lesão $(\mathbf{m m}) *$ \\
\hline 1 & 2,42 & $\mathrm{~b}$ \\
2 & 2,84 & $\mathrm{~b}$ \\
3 & 6,65 & $\mathrm{a}$ \\
4 & 6,87 & $\mathrm{a}$ \\
5 & 5,74 & $\mathrm{a}$ \\
\hline
\end{tabular}

* Médias acompanhadas de mesma letra não são significativamente diferentes, ao nível de $5 \%$, pelo teste de Tukey. (s=10). 
Tabela 4. Loci, iniciadores, motivo de repetição, número de alelos, tamanho dos alelos (pb) e informação do conteúdo de polimorfísmo (PIC) dos dez marcadores SSR utilizados para análise dos 33 isolados de Sclerotinia sclerotiorum.

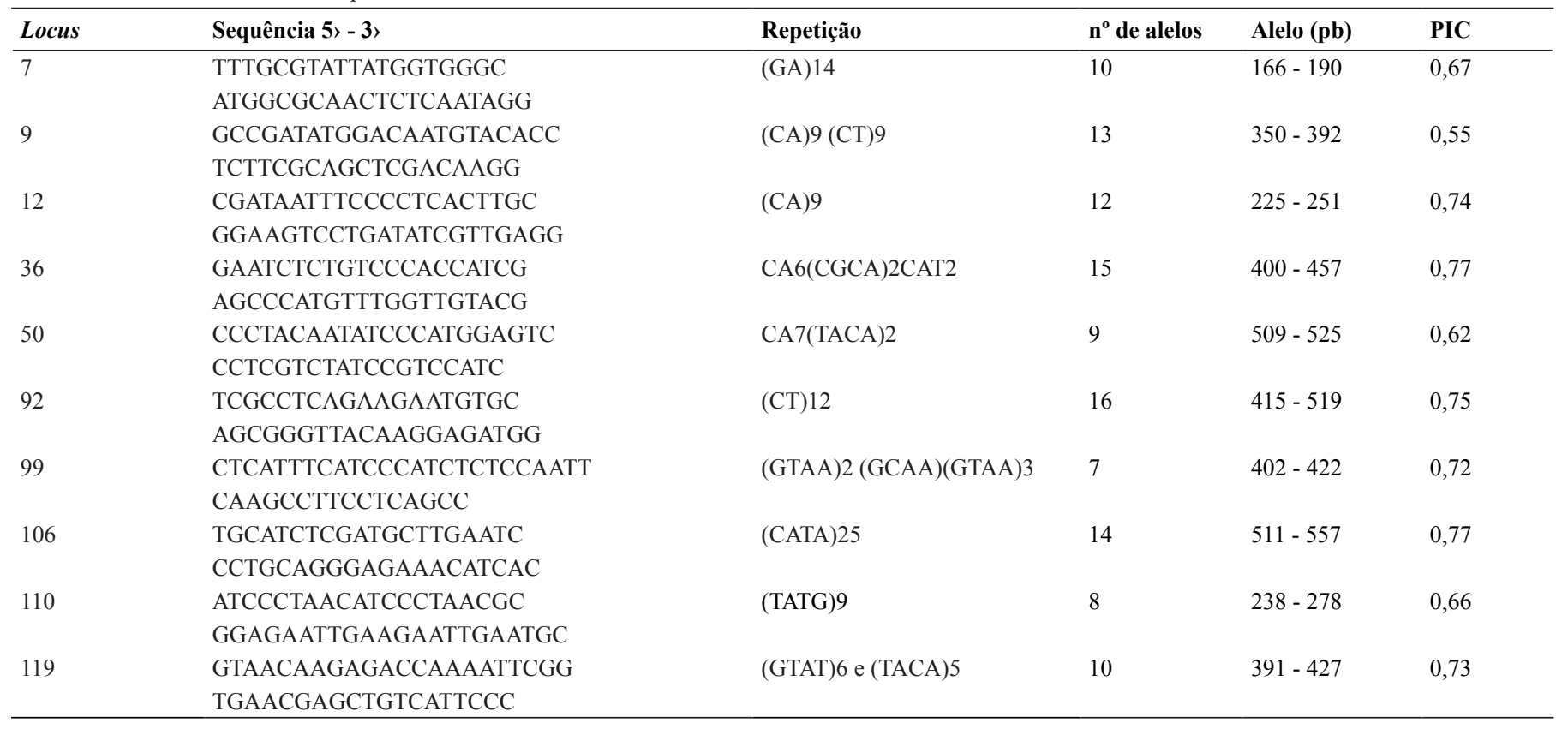

estavam em desequilíbrio de ligação, ou seja, foram independentes. Os dados com valores menores de 0,05 não foram utilizados em conjunto para avaliação, pois estavam correlacionados.

Foram detectados 114 alelos com uma média de 11 alelos por locus. O menor número de alelos identificado por locus foi de sete, tendo sido observado para o marcador 99, e o maior número de alelos foi 16, observado para o marcador 92. Alguns marcadores apresentaram alelo nulo em alguns genótipos, em especial o marcador 99, o qual foi nulo em 14 isolados. A maioria dos isolados (61\%) apresentou alelos exclusivos, sendo 55\% destes com dois alelos exclusivos, $35 \%$ com um alelo e $10 \%$ com três. Através da análise de PIC foi observado menor valor para o locus $9(0,55)$ e maior valor para os loci 106 e $36(0,77)$ (Tabela 4). Os resultados da PIC para todos os loci utilizados ficaram acima de 0,55 , sendo $60 \%$ acima de 0,72 , o que é considerado altamente informativo, conforme definido por Botstein (8).

A estimativa de diversidade genética indicou que os alelos não estão igualmente distribuídos nos diferentes estados do Sul do Brasil (locais), $(\mathrm{P}=0,0126018)$. Foi possível notar que ocorreram alelos exclusivos nos isolados, entretanto o $\mathrm{n}$ amostral foi menor que 20. Assim, o indicado seria ampliar o $\mathrm{n}$ amostral para confirmar se a exclusividade do alelo é mantida.

Para acessar o grupamento dos isolados com base no polimorfismo dos marcadores SSR, foi conduzida uma análise de componentes principais (Figura 1). Os isolados provenientes de diferentes Estados do Sul do Brasil não formaram grupos distintos, indicando que o local não foi um fator determinante da variabilidade (Figura 1A). Esta informação é corroborada pela análise de Cluster (de agrupamento) indicando que as populações menores originárias do Paraná e Rio Grande do Sul não diferem geneticamente da população maior de Santa Catarina (Figura 1B). Além disso, através do gráfico de dispersão, não foi possível observar agrupamento dos indivíduos por local e sim por similaridade.

Mesmo se analisados apenas os indivíduos originários de Santa Catarina ( $\mathrm{n}=23$ ), não haveria formação de agrupamentos (Figura 1A). Os isolados 9 e 6 de Santa Catarina se distanciaram dos demais por apresentarem o produto de amplificação com mesmo tamanho de pares de bases para os loci 7, 9 e 12 e por apresentaram alelos nulos nos loci 50, 99, 110 e 119. Já os isolados 54 e 58, do Rio Grande do Sul, amplificaram os loci 50, 99 e 110.

Através da análise de agrupamento (Figura 1B) não foi possível observar a presença de clones. A partir do nível de similaridade de 0,96 , é possível observar dois grandes agrupamentos. O agrupamento A contendo os isolados 26, 19, 05, 07, 11, 27, 52, 10, 12, 51, 30 e 31 e o agrupamento B contendo os isolados 53, 22, 03, 01, 24, 25, 02, 04, 20 e 17. Isso sugere que os isolados são próximos geneticamente, mas não são iguais.

\section{DISCUSSÃO}

Os experimentos de agressividade foram realizados com as mesmas cultivares e com os mesmos isolados, sendo a suscetibilidade dos genótipos dependente do isolado indicado pela interação de genótipo com isolado no segundo experimento. Nenhum dos genótipos testados foi resistente à doença e alguns isolados foram mais agressivos que outros, indicando a variabilidade desta característica.

Os isolados de S. sclerotiorum apresentaram comportamento variável quanto ao progresso da doença ao longo do tempo e quanto à taxa de mortalidade em ambos os experimentos. Foi possível observar que a diversidade genética entre os isolados dentro de um mesmo Estado de origem foi similar à observada entre eles, não sendo possível agrupar os isolados por local. Por ser um fungo sem especificidade de hospedeiro (22) e por apresentar diversidade genética (16) sugere-se que os diferentes níveis de agressividade encontrados neste estudo são independentes do local de origem.

A presença de dois diferentes grupos no experimento 1 evidenciou que o desenvolvimento do progresso da doença foi dependente principalmente do isolado e não do genótipo. Além disso, as análises de microssatélites demonstraram que os isolados diferiram geneticamente entre si, não sendo observados clones. Resultado semelhante foi descrito por Price \& Calhoun (21), os quais relataram que diferentes isolados de 


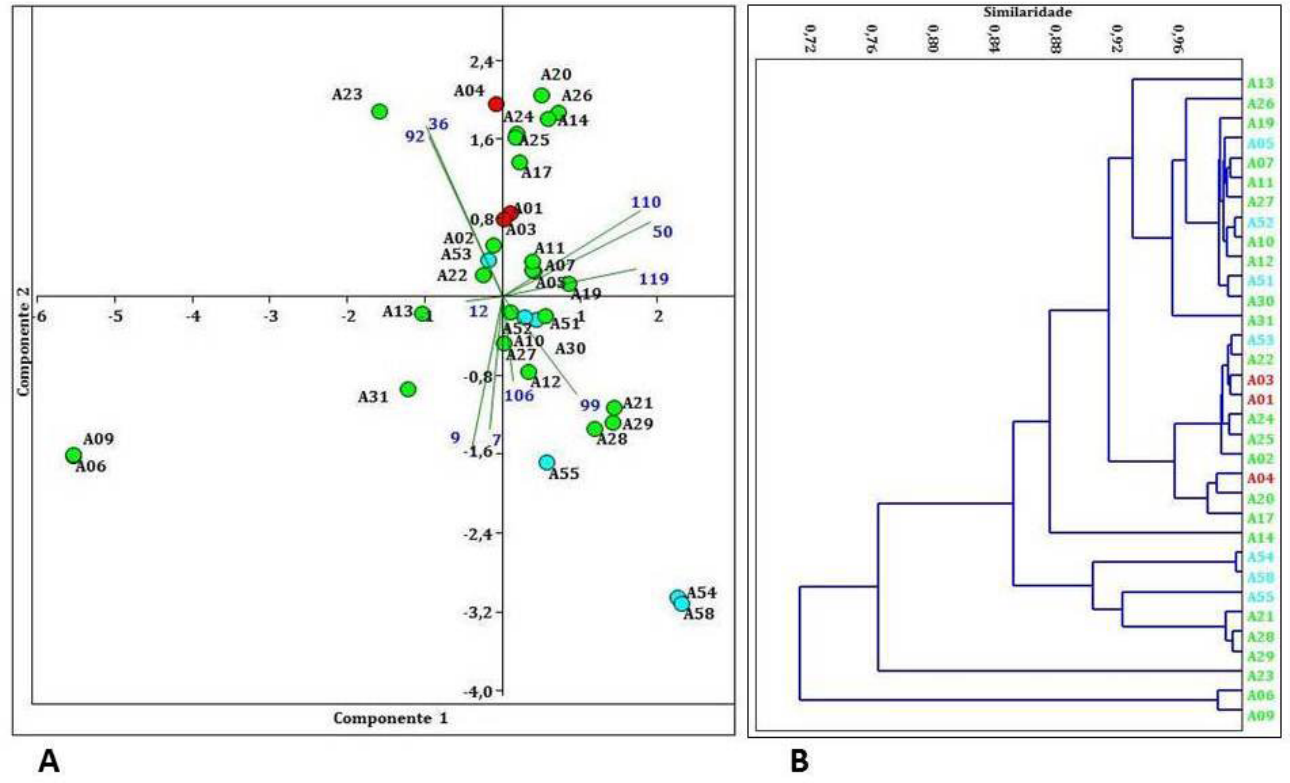

Figura 1. Similaridade dos isolados. A. Dispersão Gráfica a partir da Análise dos Principais Componentes PC1=26,8\%: e PC2=19,1\%. Isolados obtidos em diferentes estados do Sul do Brasil. Números em azul correspondem aos marcadores. Setas verdes indicam o quanto a variável marcador é responsável pelo distanciamento da amostra. B. Análise de Agrupamento pelo índice de Bray Curtis. As cores dos isolados representam os Estados de origem dos mesmos: Vermelho, Paraná; Azul, Rio Grande do Sul; Verde, Santa Catarina.

Sclerotinia causavam diferentes níveis de agressividade em distintos hospedeiros. No entanto, os grupamentos obtidos com os isolados não permitiram associação com agressividade. Por outro lado, as diferenças observadas entre os experimentos 1 e 2 sugerem que o ambiente tenha um efeito significativo na interação planta-patógeno, uma vez que a agressividade dos isolados foi muito menor no segundo experimento, quando as condições eram mais amenas.

Estudos com Brassicas inoculadas com isolados de S. sclerotiorum de diferentes países também apresentaram tamanhos variáveis de lesão (6). Os isolados do grupo 1 pertencem ao Estado de Santa Catarina, porém a diferentes municípios. O estudo de Bem-Yephet \& Britton (7) demonstra que os ascósporos são disseminados no máximo a $100 \mathrm{~m}$ da fonte de origem. Os municípios de origem dos isolados do grupo 1 distam um do outro, em média, $30 \mathrm{~km}$ em linha reta. Com isso, supõese que pela distância, os isolados do grupo 1 não sejam os mesmos. Apesar da taxa de mortalidade ter sido elevada, sugere-se que a fonte original dos inóculos não fosse a mesma, devido não só à distância entre uma lavoura e outra de onde os isolados foram coletados, mas também a não observação de clones na análise de similaridade genética. As distâncias entre os municípios de origem dos isolados do grupo 2 são ainda maiores, visto que os isolados pertenciam a três estados distintos, RS, PR e SP. As cultivares inoculadas com esses isolados apresentaram diferenças significativas quanto ao tamanho da lesão no caule. Resultado semelhante foi encontrado por Garg et al., (10) ao testarem isolados de diferentes regiões da Austrália em dois genótipos de Brassica napus e B. juncea.

Com base nos resultados de agressividade e nas análises de microssatélites, pode-se hipotetizar que os genótipos dos isolados sejam diferentes. Ge et al. (11) relataram diferenças significativas de virulência em Brassica napus e B. juncea quando inoculadas com diferentes isolados, sugerindo a possibilidade de especialização fisiológica dentro de populações de $S$. sclerotiorum.

Ao comparar ambos os experimentos, observou-se que os isolados
19 e 17 do primeiro experimento causaram $70 \%$ e $100 \%$ de morte de plantas, respectivamente, enquanto que no segundo experimento, estes mesmos isolados apresentaram interação significativa entre tempo $\mathrm{x}$ cultivar para todos os genótipos, exceto para o genótipo 4. Por outro lado, os isolados 1 e 54 causaram 10\% e 20\% de morte, respectivamente, no primeiro experimento, e foram classificados no grupo 2 , dentre os que causaram baixo percentual de morte de plantas. No segundo experimento, esses isolados foram estatisticamente menos agressivos, não diferindo a quantidade de doença entre as cultivares (Tabela 5).

O isolado 54 é originário da cultura da alface e tanto no experimento 1 quanto no experimento 2 foi pouco agressivo à cultura do tabaco, apesar de causar infecção. A capacidade de causar infecção tanto na alface quanto no tabaco sugere pouca especificidade por hospedeiro. Indicação semelhante foi relatada por Purdy (22).

Estudos sobre diversidade genética de $S$. scleroriorum foram realizados no Brasil $(12,14)$, porém em tabaco este é o primeiro relato. Dos 25 marcadores microssatélites descritos por Sirjusingh e Kohn (26), dez foram utilizados no presente estudo, os quais foram eficientes para mostrar a diversidade genética entre os isolados estudados. Esta diversidade foi confirmada pela análise do PIC, que foi $>0.5$ para todos os marcadores utilizados. Segundo Botstein (8), PIC superior a 0.5 são altamente informativos, sendo que neste estudo $60 \%$ dos marcadores apresentaram PIC $>0.72$.

Não foram observados agrupamentos pelos Estados de origem, ou seja, os isolados dos três estados estavam dispersos, mostrando que a diversidade estava entre os isolados. Também não se observou agrupamentos por agressividade nem por cultura de origem. Ao estudarem 50 isolados de $S$. sclerotiorum, a partir da amplificação de nove marcadores, Abreu \& Souza (1) observaram polimorfismo dentro da população. Além disso, Gomes et al. (12) observaram que a variabilidade foi maior dentro das populações do que entre elas. A dificuldade em observar a diversidade entre isolados por Estados pode ter sido devido à variação da quantidade (n) de isolados obtidos por 
Tabela 5. Resultado da análise das interações tempo $\mathrm{x}$ cultivar $\mathrm{x}$ isolado no experimento 2

\begin{tabular}{|c|c|c|c|c|c|c|c|}
\hline \multicolumn{8}{|c|}{ Solution for Fixed Effects } \\
\hline Effect & Cultivar & Isolado & Estimate & SE & DF & t Value & $\operatorname{Pr}>|\mathbf{t}|$ \\
\hline Tempo*Cultiv*Isolado & 1 & 1 & 0.04120 & 0.2470 & 244 & 0.17 & 0.8677 \\
\hline Tempo*Cultiv*Isolado & 1 & 10 & 0.3706 & 0.2654 & 263 & 1.40 & 0.1637 \\
\hline Tempo*Cultiv*Isolado & 1 & 11 & 0.4950 & 0.2765 & 297 & 1.79 & 0.0744 \\
\hline Tempo*Cultiv*Isolado & 1 & 21 & 0.2644 & 0.2504 & 257 & 1.06 & 0.2921 \\
\hline Tempo*Cultiv*Isolado & 1 & 54 & 0.2730 & 0.2477 & 246 & 1.10 & 0.2715 \\
\hline Tempo*Cultiv*Isolado & 1 & 56 & 0.1903 & 0.2476 & 246 & 0.77 & 0.4430 \\
\hline Tempo*Cultiv*Isolado & 2 & 1 & 0.1689 & 0.2464 & 242 & 0.69 & 0.4939 \\
\hline Tempo*Cultiv*Isolado & 2 & 17 & 0.5040 & 0.2545 & 274 & 1.98 & 0.0487 \\
\hline Tempo*Cultiv*Isolado & 2 & 19 & 0.6866 & 0.2548 & 270 & 2.69 & 0.0075 \\
\hline Tempo*Cultiv*Isolado & 2 & 21 & 0.4368 & 0.2621 & 257 & 1.67 & 0.0968 \\
\hline Tempo*Cultiv*Isolado & 2 & 54 & 0.03138 & 0.2536 & 258 & 0.12 & 0.9016 \\
\hline Tempo*Cultiv*Isolado & 2 & 56 & 0.3754 & 0.2476 & 246 & 1.52 & 0.1308 \\
\hline Tempo*Cultiv*Isolado & 3 & 1 & 0 & 0.2464 & 242 & 0.00 & 1.000 \\
\hline Tempo*Cultiv*Isolado & 3 & 4 & 0.1323 & 0.2470 & 244 & 0.54 & 0.5928 \\
\hline Tempo*Cultiv*Isolado & 3 & 10 & 0.4511 & 0.2681 & 267 & 1.68 & 0.0937 \\
\hline Tempo*Cultiv*Isolado & 3 & 19 & 0.5669 & 0.2739 & 293 & 2.07 & 0.0394 \\
\hline Tempo*Cultiv*Isolado & 4 & 10 & 0.1960 & 0.2521 & 264 & 0.78 & 0.4376 \\
\hline Tempo*Cultiv*Isolado & 4 & 11 & 0.2043 & 0.2772 & 255 & 0.74 & 0.4618 \\
\hline Tempo*Cultiv*Isolado & 4 & 17 & 0.4091 & 0.2539 & 271 & 1.61 & 0.1082 \\
\hline Tempo*Cultiv*Isolado & 4 & 19 & 0.4191 & 0.2672 & 269 & 1.57 & 0.1179 \\
\hline Tempo*Cultiv*Isolado & 4 & 21 & 0.8397 & 0.2526 & 262 & 3.32 & 0.0010 \\
\hline Tempo*Cultiv*Isolado & 4 & 54 & 0.03571 & 0.2483 & 249 & 0.14 & 0.8857 \\
\hline Tempo*Cultiv*Isolado & 4 & 56 & 0.7812 & 0.2597 & 279 & 3.01 & 0.0029 \\
\hline Tempo*Cultiv*Isolado & 5 & 1 & 0.2055 & 0.2483 & 248 & 0.83 & 0.4087 \\
\hline Tempo*Cultiv*Isolado & 5 & 4 & 0.3191 & 0.2470 & 244 & 1.29 & 0.1976 \\
\hline Tempo*Cultiv*Isolado & 5 & 10 & 0.2641 & 0.2470 & 244 & 1.07 & 0.2861 \\
\hline Tempo*Cultiv*Isolado & 5 & 11 & 0.3175 & 0.2520 & 264 & 1.26 & 0.2089 \\
\hline Tempo*Cultiv*Isolado & 5 & 17 & 0.5527 & 0.2527 & 263 & 2.19 & 0.0296 \\
\hline Tempo*Cultiv*Isolado & 5 & 19 & 0.5799 & 0.2653 & 269 & 2.19 & 0.0297 \\
\hline Tempo*Cultiv*Isolado & 5 & 21 & 0.2573 & 0.2490 & 252 & 1.03 & 0.3024 \\
\hline Tempo*Cultiv*Isolado & 5 & 54 & 0.2469 & 0.2498 & 254 & 0.99 & 0.3240 \\
\hline Tempo*Cultiv*Isolado & 5 & 56 & 0.2234 & 0.2490 & 252 & 0.90 & 0.3706 \\
\hline
\end{tabular}


Estado. Os Estados do Rio Grande do Sul e Paraná apresentaram n muito baixo ( $n=7$ e $n=3$, respectivamente) para serem comparados com o " $n$ " de Santa Catarina $(n=23)$. Esse fato pode ser explicado pelo local de ocorrência da doença, a qual, na lavoura do tabaco é mais comum na região de Santa Catarina, sendo nos estados do Rio Grande do Sul e Paraná pouco frequente.

A variabilidade genética dos isolados também pode ser observada pelo número de alelos. Neste trabalho foram encontrados 114 alelos, variando de 8 a 17 por locus. Gomes et al. (12) encontraram 102 diferentes alelos, variando de 6 a 18 por locus, sendo a variação semelhante à observada neste estudo. Entretanto, Atallah et al. (4), ao utilizarem 6 marcadores diferentes e 5 iguais aos utilizados neste trabalho, verificaram que o número de alelos foi mais baixo, de 2 a 5 por locus.

Segundo Sokal \& Sneath (27), a análise de cluster engloba técnicas relacionadas que medem a similaridade ou a distância entre dados, os quais são expressos em uma árvore ultramétrica. Apesar da maioria dos isolados analisados neste trabalho apresentarem similaridade genética superior a 0,92 , nenhum isolado foi geneticamente igual ao outro, indicando ausência de clones. Porém, clones são facilmente encontrados em lavouras devido à sobrevivência de escleródios no solo $(9,17)$. Esses resultados foram observados em lavouras de canola, soja, repolho, kiwi na América do Norte, Europa, Nova Zelândia, Austrália (17) e em feijão no Brasil (14).

A ausência de clones e a diversidade entre os isolados encontrados neste estudo indicam que o patógeno é variável dentro de pequenas áreas geográficas (por municípios). Estes dados são semelhantes aos observados no cerrado brasileiro em análises de isolados originários de feijão irrigado (12).

A variabilidade dentro de pequenas áreas geográficas pode também estar associada aos valores do conteúdo de informação do polimorfismo (PIC média $=0,70$ ). Além disso, $61 \%$ dos isolados apresentaram alelos exclusivos. Com isso, sugere-se que a variabilidade dos isolados deste estudo é moderada. A presença de alelos exclusivos é de grande importância para otimização de análises de diversidade de isolados de S. sclerotiorum. O locus 36, neste estudo, teve nove alelos exclusivos, o qual poderá ser um locus de referência para futuras pesquisas devido ao número de alelos exclusivos.

Pode-se concluir neste estudo que a suscetibilidade das cultivares de tabaco foi dependente da maior agressividade do isolado. A ausência de clones indica que a população de $S$. sclerotiorum em lavouras de tabaco é variável. As análises de diversidade genética dos isolados avaliados sugerem que o patógeno é variável dentro de pequenas áreas geográficas.

Por se tratar de uma cultura que não possui cultivares resistentes ao patógeno, acredita-se que o manejo integrado possa ser a ferramenta mais apropriada para minimizar os danos causados pela doença nas lavouras de tabaco.

\section{REFERÊNCIAS}

1. Abreu, M.J.; Souza, E.A. Investigation of Sclerotinia sclerotiorum strains variability in Brasil. Genetics and Molecular Research, Ribeirão Preto, v.14, n.2, p.6879-6896, 2015.

2. Afubra. Associação dos Fumicultores do Brasil. Disponível em: http://www. afubra.com.br. Acesso em: 02/04/2014.

3. Aghajani, M.A.; Safaie, N. Alizadeh, A. Yield loss assessment of Sclerotinia stem rot of canola in Iran. Journal of Crop Protection, Tehran, v. 2, n.2, p. 229-240, 2013.

4. Atallah, Z.K; Larget, B.; Chen, X.; Johnson, D.A. High genetic diversity, phenotypic uniformity, and evidence of outcrossing in Sclerotinia sclerotiorum in the Columbia Basin of Washington State. Phytopathology, St Paul, v. 94, n7, p. 737-742, 2004.

5. Attanayake, R.N.; Tennekon, V.; Johnson D.A.; Porter, L.D.; del Rio-MenM donza, L.; Jiang, D.; Chen, W. Inferring outcrossing in the homothallic fungus Sclerotinia sclerotiorum using linkage disequilibrium decay. Heredity, Harlow, v. 113, n.4, p. 353-363, 2014.

6. Barbetti, M.J.; Banga, S. k.; Fu, T.D.; Li, Y.C.; Singh, D.; Liu, S.Y.; Ge, X.T.; Banga, S.S. Comparative genotype reactions to Sclerotinia sclerotiorum within breeding populations of Brassica napus and B. juncea from India and China. Euphytica, Wageningen v. 197, n1, p. 47-59, 2014

7. Ben-Yephet, Y.; Bitton, S. Use of a selective medium to study the dispersal of ascospores of Sclerotinia sclerotiorum. Phytoparasitica, Cham, v.13, n.1, p.33-40, 1985.

8. Botstein, D.; White, R.L.; Skolnick, M.; Davis, R.W. Construction of a genetic linkage map in man using restriction fragment length polymorphisms. The American Journal of Human Genetics, Cambridge, v.32, n.3, p. 314-331, 1980.

9. Clarkson, J.P.; Coventry, E.; Kitchen, J.; H. E. Carter, H.E.; Whipps, J.M. Population structure of Sclerotinia sclerotiorum in crop and wild hosts in UK. Plant Pathology, Loughborough v. 62, n.2, p. 309-324, 2013.

10. Garg, H.; Hohn, L.M.; Andrew, M.; Ku, H.; Sivasithamparam, K.; Barbetti, M.J. Pathogenicity of morphologically different isolates of Sclerotinia sclerotiorum with Brassica napus and B. juncea genotypes. European Journal of Plant Pathology, Wageningen v. 126, n.3, p. 305-315, 2010.

11. Ge, X. T.; Li, Y.P.; Wan, Z. J.; You, M.P.; Finnegan, P.M.; Banga, S.S.; Sandhu, P.S.; Garg, H.; Salisbury, P.A.; Barbetti, M.J. Delineation of Sclerotinia sclerotiorum pathotypes using differential resistance responses on Brassica napus and B. juncea genotypes enables identification of resistance to prevailing pathotypes. Field Crops Research, Amsterdam v. 127, p. 248-258, 2012

12. Gomes, E. V.; do Nascimento, L.B.; de Freitas, M.A.; Nasser, L.C.B.; Petrofeza, S. Microsatellite markers reveal genetic variation within Sclerotinia sclerotiorum populations in irrigated dry bean crops in Brazil. Journal of Phytopathology, Weinheim, v. 159, n.2, p. 94-99, 2011.

13. Grabicoski, E. M. G. Caracterização Morfológica e Patogênica de Isolados de Sclerotinia sclerotiorum (Lib.) de Bary e Deteção em sementes de Soja. 2012. 136f. Dissertação (Mestrado) - Programa de Pós-Graduação em Agronomia - Área Concentração Fitopatologia, Universidade Estadual de Ponta Grossa - PR, 2012.

14. Lehner M.S.; Paula Júnior, T.J.; Hora Júnior, B.T.; Teixeira, H.; Vieira, F.R.; Carneiro, J.E.S.; Mizubuti, E.S.G. Low genetic variability in Sclerotinia sclerotiorum populations from common bean fields in Minas Gerais State, Brazil, at regional, local and micro-scales. Plant Pathology, Loughborough, v. 64, n.4, p. 921-931, 2015.

15. Lehner, M d'S. Estrutura Genética da População de Sclerotinia sclerotiorum em Feijoais de Minas Gerais. 2011. 33f. Dissertação (Mestrado) - Programa de Pós-Graduação em Genética e Melhoramento, Universidade Federal de Viçosa, Viçosa, MG, 2011.

16. Li, M.; Jia, R.; Na, R.; Hou, Y.; Bu, H.; Zhou, H.; Zhao, J. Genetic diversity of Sclerotinia sclerotiorum within a single sunflower field in Wenquan, Xinjiang Province, China. Journal of Plant Pathology, Pisa, v.98, n.1, p.43-53, 2016.

17. Malvaréz, G.; Carbone, I, Grünwald, J.; Subbarao, K.V.; Schafer, M.; Kohn, L.M. New Populations of Sclerotinia sclerotiorum from Lettuce in California and Peas and Lentils in Washington. Phytopathology, St Paul, v.97, n.4, p. 470-483, 2007

18. Mert-türk, F.; Ipek, M.; Mermer, D.; Nicholson, P. Microsatellite and morphological markers reveal genetic variation within a population of Sclerotinia sclerotiorum from oilseed rape in the Çanakkale Province of Turkey. Journal of Phytopathology, Weinheim, v. 155, n.3, p. 182-187, 2007.

19. Otto-Hanson, L.; Steadman, J.R.; Higgins, R.; Eskridge, K.M. Variation in Sclerotinia sclerotiorum bean isolates from multisite resistance screening locations. Plant Disease, St Paul, v. 95, n.11, p.1370-1377, 2011.

20. Pariaud, B.; Ravigné, V.; Halkett, F.; Goyeau, H.; Carlier, J.; Lannou, C. Aggressiveness and its role in the adaptation of plant pathogens. Plant Pathology, Loughborough, v. 58, n.3, p. 409-424, 2009.

21. Price, k.; Calhoun j. Pathogenicity of isolates of Sclerotinia sclerotiorum (Lib.) de Bary to several hosts. Phytopathology,St Paul, v. 83, p. 232238, 1975.

22. Purdy, L. H. Sclerotinia sclerotiorum: history, diseases and symptomatology, 
host range, geographic distribution, and impact. Phytopathology, St Paul, v. 69, n. 8 , p. $875-880,1979$.

23. Rousset, F. Genepop'007: a complete reimplementation of the Genepop software for Windows and Linux. Molecular Ecology Resources, Medford, v.8, p.103-106, 2008.

24. Scott J. B.; Gent, D.H.; Pethybridge, S.J.; Hay, F.S. Spatiotemporal characterization of Sclerotinia crown rot epidemics in pyrethrum. Plant Disease, St Paul, v. 98, n.2, p. 267-274, 2014

25. Sexton, A.C.; Howlett, B.J.. Microsatellite markers reveal genetic differentie ation among populations of Sclerotinia sclerotiorum from Australian canola fields. Current Genetics, Berlin, v. 46, n.6, p. 357-365, 2004.

26. Sirjusingh C.; Kohn, L.M. Characterization of microsatellites in the fungal plant pathogen, Sclerotinia sclerotiorum. Molecular Ecology Notes, Oxford, n1., p. 267-269, 2001.

27. Sokal, R.R.; Sneath, P.H.A. Principles of numerical taxonomy. Current Contents/Agriculture, Biology \& Environmental Sciences, Philadelphia, n. 46, p. $14,1982$.
28. Souza D. A. de. Efeito da seleção recorrente para resistência à macha angular na reação ao mofo branco em alelos SSR de progênies de feijão. 2012. 98p. Dissertação (Mestrado) - Universidade Federal de Lavras, Lavras, 2012.

29. Viana, F. C.; Berger, I. J.; Duarte, V. Characterization of Ralstonia solanacearum Smith populations in tobacco (Nicotiana tabacum L.) from Brazil. Tropical Plant Pathology, Viçosa, v.37, n. 2, p. 123-129, 2012.

30. Viteri D.M.; Otto, K.; Terán, H.; Schwartz, H.F.; Singh, S.P. Use of four Sclerotinia sclerotiorum isolates of different aggressiveness, three inoculations per plant, and delayed multiple evaluations to select common beans with high levels of white mold resitance. Euphytica, Wageningen, v 204, n.2, p. 457-472, 2015.

31. Yanar, Y; Onaran, A. Mycelial compatibility groups and pathogenicity of Sclerotinia sclerotiorum (Lib.) De Bary causal agent of white mold disease of greenhouse grown cucumber in Antalya-Turkey. African Journal of Biotechnology, Ebène, v. 10, n.19, p. 3739-3746, 2011. 